\title{
Report on the Second International Conference on Health Sciences and Medical Technologies
}

\section{Type of article: Editorial}

\author{
Abdeldjalil KHELASSI \\ Editor-in-chief of Medical Technologies Journal \\ Knowledge and Information Research Team KIERT, Computer Sciences Department, \\ AbouBekerBelkaid University of Tlemcen, Algeria. \\ Khelassi.a@gmail.com
}

\begin{abstract}
ICHSMT'17: the second edition of International Conference on Health Sciences and Medical Technologies 2017 held from 10 to 12 October 2017 at Tlemcen, Algeria. With cooperation of Knowledge Kingdom Publishing and Mehr Publishing Group the conference took place at the Renaissance hotel. Regrouping contributors from fifteen countries, an interdisciplinary program was composed aiming to contribute to the scientific progress on health sciences and medical technologies.
\end{abstract}

Keywords: Conference report, Health sciences, Medical technology, Algeria, Tlemcen

Corresponding author:DrAbdeldjalil KhelassiComputer Sciences Department, Abou Beker Belkaid University of

Tlemcen, Algeria. Email: Khelassi.a@gmail.com

() 2017-2018 KNOWLEDGE KINGDOM PUBLISHING.

\section{Introduction}

The second edition of International Conference on Health Sciences and Medical Technologies ICHSMT'17 was held at Tlemcen, Algeria, from 10 to 12 October 2017. It is an interdisciplinary platform for medical findings and innovations [1]. This edition has contributors from 15 nations: Algeria, Germany, Iran, Switzerland, Netherland, Denmark, Malaysia, Canada, France, Morocco, Brazil, Italy, Belgium, Egypt, and the United States of America. The author's affiliations were from various departments such as medicine, biology, physics, chemical sciences, computer science, environment, pharmacy, electrical and electronic engineering, and mechanical engineering.

The conference included three Keynotes [2, 3, and 4] on medical imaging and scientific publishing, four international workshops, and four sessions:

Table1: ICHSMT' 17 workshops and sessions.

\begin{tabular}{|l|l|}
\hline Workshops and sessions & Number of contributions \\
\hline International Workshop on Medical Technologies IWMT'17 & 15 \\
\hline International Workshop on Cancer and Public Health 2017 & 7 \\
\hline $\begin{array}{l}\text { IWG: International Workshop on Gynecology } \\
\begin{array}{l}\text { IWPCBS: International Workshop on Preclinical and Clinical } \\
\text { Basic Sciences }\end{array}\end{array}$ & 9 \\
\hline Session 1: Infectious Diseases and Microbiology & 7 \\
\hline $\begin{array}{l}\text { Session 2: Genetical Items } \\
\text { Session 3: Clinical specialties such as Gastroenterology, Urology, } \\
\text { Cardiology, Dermatology }\end{array}$ & 3 \\
\hline Session 4: Publication and Ethics & 2 \\
\hline
\end{tabular}




\section{Conference sponsors}

We appreciate all sponsors for their contributions. The main list of contributors comprised:

1. Mehr Publishing Group

2. Knowledge Kingdom Publishing

3. Electronic Physician Journal

4. Medical Technologies Journal

5. Biomedical Engineering Laboratory (University of Tlemcen) In addition, the secondary list covered sponsors like:

6. Faculty of technology (University of Tlemcen)

7. Renaissance hotel

\section{Contributions and Prices}

The published book [5] contains all accepted abstracts of contributions presented at ICHSMT'17. There were 90 submissions. The committee decided to accept 60 presentations, the acceptance rate was $66.66 \%$.

Three research articles were selected for prices proposed by Electronic Physician Journal. The first price was awarded to Ryad Temmar et al [6] about an embedded medical application. The second price was granted to Zaki Moqaddem et al [7] about his epidemiological survey of prostate cancer in Tlemcen. The third price was conferred to Abdelfettah MEZIANE et al [8] about brain cancer imaging application.

\section{Conclusion}

The conference was imbedded into nice and cool surroundings with an important participation of young doctoral students and universities. Although the estimated program was realized at $73.33 \%$ of all scheduled presentations, and some technical problems; the achieved presentations and interdisciplinary discussions on the conference were very important, stimulating and exceptional. Several project and contract drafts were initially generated and further processed.

\section{Declaration of conflicts}

No conflicts

\section{Authors' biography}

Dr. Eng Abdeldjalil Khelassi: is an associate professor of Informatics at Abou Bekr Belkaid University of Tlemcen. The chair of International Conference on Health Sciences and Medical Technologies. Head of Knowledge and Information Engineering Research Team. Associate editor at Electronic Physician. 


\section{References}

1. Khelassi, Abdeldjalil. "Conference Report: International Conference on Health Sciences and Medical Technologies, Tlemcen, Algeria 27-29 September 2016 ICHSMT'16." Electronic physician 8.10 (2016): 3032. https://doi.org/10.19082/3032

2. Zaidi, Habib. " Multimodality molecular imaging: Paving the way for personalized medicine." Medical Technologies Journal, 1.3 (2017): 44-46. https://doi.org/10.26415/2572-004X-vol1iss3p44-46

3. Hassan, Syed Tajuddin Bin Syed, JalalianMehrdad, \&SalizaMohd Elias." Critical Literature Review: Preparation Strategies." Medical Technologies Journal [Online], 1.3 (2017): 47-47. https://doi.org/10.26415/2572-004X-vol1iss3p47-47

4. Hassan, Syed Tajuddin Bin Syed, SalizaMohd Elias, \&JalalianMehrdad." Research Excellence: The Imperative Primers." Medical Technologies Journal [Online], 1.3 (2017): 48-49. https://doi.org/10.26415/2572-004X-vol1iss3p48-49

5. KHELASSI: Abstract Book: ICHSMT'17,Tlemcen 10-12 October 2017, International Conference on Health Sciences and Medical Technologies 2017. 10/2017; Mehr Publishing. ISBN: 978-6009666133.

6. RyadTemmar, Mohamed Ouslim, and Mohammed Mekri. In: Khelassi A, editor. The new design of a remote real time embedded medical platform; Abstracts Book of ICHSMT'17- International Conference on Health Sciences and Medical Technologies; 2017 Oct 10-12; Tlemcen, Algeria. Mehr publishing; 2017.p. 47.

7. MOQADDEM.Z1, AOUAR.A, KAZI.N, et al. In: Khelassi A, editor. Risk factors for prostate cancer in the population of Tlemcen, West Algeria; Abstracts Book of ICHSMT'17- International Conference on Health Sciences and Medical Technologies; 2017 Oct 10-12; Tlemcen, Algeria. Mehr publishing; 2017.p. 47.

8. Abdelfettah MEZIANE, Saïd MAHMOUDI, and Mohammed Amine CHIKH. In: Khelassi A, editor. Brain Structures Segmentation by using Statistical Models; Abstracts Book of ICHSMT'17International Conference on Health Sciences and Medical Technologies; 2017 Oct 10-12; Tlemcen, Algeria. Mehr publishing; 2017.p. 47. 